\title{
TATA RIAS PENGANTIN AGUNG KABUPATEN TABANAN
}

\author{
K.M. Widi Hutami ${ }^{1}$, I.D.A. Made Budhyani ${ }^{1)}$, I.G. Sudirtha ${ }^{2)}$ \\ Program Studi Pendidikan Kesejahteraan Keluarga, Fakultas Teknik dan Kejuruan \\ Universitas Pendidikan Ganesha \\ Singaraja, Indonesia \\ e-mail: monik.widi.hutami@undiksha.ac.id, ayu.budhyani@undiksha.ac.id, \\ gede.sudirtha@undiksha.ac.id
}

\begin{abstract}
ABSTRAK
Penelitian ini bertujuan untuk mendeskripsikan (1) tata rias wajah (2) tata rias rambut, (3) tata busana (4) aksesoris dari tata rias pengantin Agung Kabupaten Tabanan. Jenis penelitian merupakan penelitian deskriptif. Metode pengumpulan data yang dilakukan dengan cara observasi dan wawancara. Sumber data dari A.A. Ayu Ketut Agung sebagai informan kunci, selaku pemilik LKP Salon Agung dan Penglingsir Puri Agung Kabupaten Tabanan, Sagung Oka Pradnyawati selaku pemiliki LKP Salon Anggun dan Made Rahayuni selaku pemilik salon Candra Dewi. Penelitian ini dilaksanakan pada bulan Juni sampai Juli tahun 2019 di Kabupaten Kabupaten Tabanan. Instrumen penelitian ini adalah lembar observasi dan lembar wawancara. Analisis data yang digunakan adalah teknik deskriptif. Hasil penelitian menunjukkan bahwa tata rias pengantin Agung Kabupaten Tabanan terdiri dari (1) tata rias wajah untuk pengantin pria yaitu alis- alis, perona mata, perona pipi, eyeliner, perona bibir dan tata rias wajah untuk pengantin wanita yaitu serinata, alis-alis, hiasan mata, hidung, perona pipi, hiasan bibir, gecek dan penampel pelengan. (2) tata rias rambut untuk pengantin pria menggunakan udeng emas dan tata rias rambut untuk pengantin wanita yaitu pembuatan semi, petitis meruncing berbentuk jantung hati, bunga mawar, bunga cempaka kuning, bunga cempaka putih, bunga sandat, bunga emas, bancangan, bunga kap, bunga kompyong, puspalembo, sanggul gelung tanduk. (3) tata busana untuk pengantin pria menggunakan baju kerah berdiri dengan hiasan emas, umpal prada, wastra prada, saput songket dan tata busana untuk pengantin wanita menggunakan selendang once jawa, selendang ktengsun, wastra songket, tapih prada, sabuk prada. (4) aksesoris untuk pengantin pria menggunakan rumbing dan keris dan aksesoris untuk pengantin wanita menggunakan kalung, subeng, gelang naga satru, gelang kana, sabuk emas, dan cincin.
\end{abstract}

Kata kunci : aksesoris, busana, tata rias, pengantin agung Kabupaten Tabanan

\begin{abstract}
This study aims to describe (1) facial make-up (2) hair make-up (3) fashion (4) accessories from bridal make-up Agung Kabupaten Tabanan. Type of research used is descriptive research. Data collection methods are done by observation and interviews. Source of data from A.A. Ayu Ketut Agung as the owner of the Agung salon LKP and Agung Kabupaten Tabanan castle chancellor, Sagung Oka Pradnyawati as the owner of the Anggung LKP, and Made Rahayuni as the owner of the Candra Dewi salon. This research was conducted from June to July 2019 in Kabupaten Tabanan Regency. The instrument of this study was the observation sheet and interview sheet. Data analysis used was descriptive technique. The results of this study indicate that bridal make-up Agung Kabupaten Tabanan for brides consists of (1) face make-up namely serinata, eyebrows, eye decoration, nose decoration, blush on, lip colour, gecek and penampel pelengan and bridal make-up Agung Kabupaten Tabanan for the groom is face make-up namely eyebrows, eye decoration, blush on, eyeliner, lip colour. (2) Hairdressing on the bride namely making semi, petitis heart shaped, roses, white cempaka flowers, yellow cempaka flowers, ylang flowers, golden flowers, bancangan, bunga kap, kompyong, puspalembo, and sanggul gelung tanduk and the groom's hair dressing is using udeng emas. (3) Fashion used on the bride is the scarf once jawa, the scarf ktengsun, wastra songket, tapih prada, sabuk prada and the clothes used are baju kerah emas, umpal prada, saput songket, and wastra prada. (4) The accessories used on the bride are the rings, necklaces, gelang nagasatru, gelang kana, and sabuk emas and the accessories used are rumbing and keris.
\end{abstract}

Keyword : Accessories, fashion, make-up, bridal Kabupaten Tabanan 


\section{PENDAHULUAN}

Indonesia sebagai negara kepulauan dikenal memiliki keragaman suku bangsa, bahasa dan kebudayaannya yang beraneka ragam. Keaneka ragaman suku bangsa dan kebudayaan itu pada hakekatnya adalah satu dan telah memberi identitas khusus dan menjadi modal dasar sebagai landasan pengembangan budaya bangsa. Salah satu unsur kebudayaan yang paling menonjol seperti misalnya kesenian, merupakan unsur yang dominan dalam mewarnai kebudayaan Indonesia. Salah satu unsur itu adalah tata rias pengantin. Tata rias pengantin yang erat hubungannya dengan sistem kepercayaan mempunyai nilai yang tinggi dan beraneka ragam sesuai dengan sistem nilai-nilai yang dimiliki oleh masyarakat Indonesia (Wibowo, 1987:70). Setiap daerah yang ada di Indonesia memiliki jenis tata rias pengantin yang berbeda. Seperti provinsi Bali yang terkenal akan keindahan alam, kebudayaan dan tradisi Bali yang masih dilestarikan keunikannya, serta tata rias pengantin Bali yang memiliki keunikan dan ciri khas tersendiri yaitu menggunakan susunan perhiasan bernuansa keemasan yang digunakan pengantin wanita dan juga pengantin pria yang tentunya berbeda dari daerah lainnya.

Tata rias pengantin merupakan suatu kegiatan tata rias wajah pada pengantin yang bertujuan untuk menonjolkan kelebihan yang ada dan menutupi kekurangan wajah pengantin. Tata rias pengantin Bali adalah suatu tata rias pengantin yang digunakan pada saat upacara pernikahan adat Bali yang bertujuan untuk mempercantik pengantin dan sudah dilakukan sejak dulu yang diturunkan secara turun temurun sesuai dengan budaya yang dipercayai oleh masyarakat setempat (Mahligai, 2009:27). Tata rias pengantin Bali memiliki 3 tingkatan yaitu tata rias pengantin Bali Nista (sederhana), Madya (menengah), Utama (tertinggi). Pada zaman dulu tata rias pengantin madya dan utama hanya dipergunakan oleh golongan triwangsa sedangkan tata rias pengantin nista dipergunakan oleh orang jaba. Namun pada akhir- akhir ini, pemakaian tata rias menurut aturan- aturan tadi sudah tidak terlalu diperhatikan, hal ini sangat tergantung dari kemampuan ekonomi dari pengantin yang akan menyelenggarakan upacara pernikahan (Dharmika, 1988:81).

Tata rias pengantin Bali Agung merupakan tata rias pengantin yang paling tinggi tingkatannya dan paling mewah. tata rias pengantin Bali Agung dibagi menjadi dua bagian yaitu tata rias wajah dan tata rias rambut, tata rias wajah pengantin Bali Agung sangat sederhana hanya menggunakan bedak atau boreh miik (Mertami,2003:15). Tata rias rambut pada pengantin Bali Agung yaitu penataan rambutnya paling tinggi dan mewah tingkatannya dibandingkan penataan rambut pada tata rias pengantin Nista dan Madya. Pada tata rias pengantin Bali Agung penataan rambut diawali dengan pembentukan semi dan dilanjutkan pemasangan bunga. Aksesoris dan hiasan kepala yang digunakan oleh pengantin terbuat dari emas serta busana yang digunakan pun menggunakan kain prade yang membuat pasangan pengantin terlihat anggun, cantik dan menarik.

Tata rias wajah pengantin Bali Agung adalah suatu cara seseorang untuk mempercantik diri khususnya pada bagian wajah namun memiliki spesifikasi pada dahi yaitu pembentukan srinata dan pemberian gecek. Bagian- bagian tata rias wajah yang memiliki untuk tata rias pengantin Bali Agung yaitu:

1. Srinata adalah gambaran dahi untuk membentuk dahi agar kelihatan lebih indah dan bagus, sesuai dengan tata rias pengantin Bali yang berfungsi untuk menyeimbangkan bentuk dahi serta memiliki makna kedewasaan baik fisik maupun batin.

2. Gecek adalah tanda titik yang berwarna merah di antara pangkal alis di tengah- tengah, yang mempunyai arti pancaran dari Sang Hyang Widhi. Untuk pemberian warna merah 
menggunakan lipstik berwarna merah (Usodiningtyas, 2010:30).

3. Alis-alis, bentuk alis yang ideal itu seperti daun intaran yang bentuknya dari pangkal keujung semakin meruncing serta memiliki makna bahwa kekuatan wanita bali dalam menghadapi kehidupan untuk mencapai hidup yang indah tanpa ada batas dan tidak pernah ada lelahnya (Wiartini,2016).

Penataan rambut pada tata rias ini diawali dengan pembuatan semi yang diberikan "malem" untuk mengimbangi srinata dan bunga sasak yang dibentuk seperti engkug-engkugan (sunggaran) melengkung ke dalam menuju belakang telinga. Selanjutnya mepusungan/ sanggung dengan bantuan gelung kucit yang dilengkapi dengan bunga cempaka dan bunga sandat (Pujiastuti, 2015). Adapun bagian-bagian pada tata rias rambut pengantin Bali Agung yaitu:

1. Semi adalah suatu bentuk rambut untuk mengimbangi riasan srinata serta hiasan bunga yang berfungsi untuk menyelaraskan bentuk dahi sehingga terlihat lebih anggun.

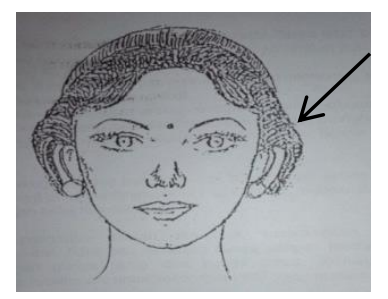

Gambar 2. Semi

Sumber: Mertami,2003

2. Gelung kucit berfungsi untuk penyangga pemasangan bunga cempaka putih dan kuning dan bunga sandat. Gelung kucit memiliki makna tahap menuju berumah tangga akan menjadi suami istri.

3. Hiasan kepala memiliki makna melambangkan keindahan, hiasan kepala yang digunakan yaitu bunga mawar, bunga cempaka putih, bunga cempaka kuning dan bunga sandat.

Busana yang digunakan oleh pengantin wanita dan pengantin pria dalam tata rias pengantin Bali Agung yaitu pada pengantin wanita menggunakan tapih prada, wastra prada, sabuk prada, selendang prada. Sedangkan pada pengantin pria menggunakan kamen prada, kampuh prada, umpal prada. Pada tata rias pengantin Bali Agung pengantin pria dan pengantin wanita menggunakan aksesoris yang berbeda yaitu pada pengantin wanita menggunakan subeng, badong, petitis, sabuk pending, gelang dan cincin. Sedangkan pada pengantin prias menggunakan keris, gelang, dan rumbing.

Bali memiliki 8 kabupaten dan 1 kota Madya yaitu Badung, Buleleng, Jembarana, Bangli, Karangasem, Klungkung, Gianyar, Kabupaten Tabanan dan kota Madya Denpasar. Di masingmasing kabupaten tersebut memiliki keunikan dan ciri khas tersendiri yang membedakan antara Kabupaten satu dengan Kabupaten lainnya di Bali. Salah satunya pada tata rias pengantinnya memiliki keunikan dan ciri khas pada setiap kabupaten yang ada di Bali (Agung, 2004:10). Seperti tata rias pengantin Agung Kabupaten Tabanan, tata rias pengantin Agung Kabupaten Tabanan memiliki keunikan dan ciri khas tersendiri dari tata rias pengantin Bali Agung lainnya. Tata rias pengantin Agung Kabupaten Tabanan belum dipakemkan dan hanya digunakan oleh golongan yang berkasta sampai sekarang pun tradisi itu tetap digunakan bahwa tata rias pengantin Agung Kabupaten Tabanan hanya digunakan oleh orang- orang yang tinggal di puri dan griya. Tata rias pengantin ini mempunyai ciri khas tersendiri yang dapat dilihat dari tata rias rambutnya yaitu menggunakan sanggul gelung tanduk dengan hiasan potongan janur kecil- kecil, bunga hidup dibagian depan seperti mawar, bunga sandat dan cempaka putih dan kuning, menggunakan bancangan dan petitis meruncing berbentuk jantung hati, sedangkan pada pengantin laki- laki 
menggunakan udeng emas yang dilengkapi dengan bunga pucuk emas. Ciri khas juga dapat dilihat dari busana pengantin yang digunakan yaitu selendang once jawa dan selendang ktengsun (selendang merah polos) sedangkan pada busana pengantin pria menggunakan baju kerah emas (Novita Dewi:2018).

Berdasarkan hasil penyebaran angket (28 Januari 2019) ke masyarakat yang ada di Kabupaten Tabanan sebanyak 50 lembar angket yaitu bahwa $10 \%$ masyarakat di kabupaten Tabanan mengetahui tata rias pengantin Kabupaten Tabanan, 14\% masyarakat di Kabupaten Tabanan ragu- ragu mengetahui tata rias pengantin Kabupaten Tabanan dan $76 \%$ masyarakat di kabupaten Kabupaten Tabanan masih banyak belum mengetahui dan menggunakan tata rias pengantin Kabupaten Tabanan di setiap upacara pernikahan.

Selanjutnya hasil wawancara yang dilakukan di beberapa pemilik salon daerah Kabupaten Tabanan diantaranya pemilik salon Lalima, pemilik salon M2, pemilik salon Mahadewi, pemilik salon Candra Dewi, pemilik salon Anggun menyatakan bahwa tata rias pengantin Agung Kabupaten Tabanan belum dipakemkan dan hanya digunakan oleh orang- orang yang berkasta dan yang tinggal di dalam puri, sehingga masih ada masyarakat yang belum mengetahui bentuk tata rias pengantin Agung Kabupaten Tabanan, minat masyarakat lebih dominan pada tata rias pengantin Bali Agung Badung dan tata rias pengantin modifikasi serta terdapat perbedaan dari tata rias pengantin Bali Agung Badung dengan tata rias pengantin Agung Kabupaten Tabanan.

Pemaparan di atas menyatakan bahwa tata rias pengantin Agung Kabupaten Tabanan hanya digunakan dikalangan orang berkasta dan belum dipakemkan. Dari latar belakang di atas maka peneliti akan melakukan penelitian dengan judul "Tata Rias Pengantin Agung Kabupaten Tabanan". Penelitian ini bertujuan untuk mendeskripsikan tata rias wajah, tata rias rambut, tata busana dan aksesoris dari tata rias pengantin Agung Kabupaten Kabupaten Tabanan.

\section{METODE PENELITIAN}

Penelitian yang dilakukan adalah penelitian deskriptif. Teknik pengumpulan data yang dilakukan dalam penelitian ini adalah metode observasi dan wawancara. Penelitian ini bertujuan untuk mendeskripsikan bentuk dari tata rias pengantin Agung Kabupaten Tabanan. Penelitian ini dilaksanakan pada bulan Juni sampai Juli di Kabupaten Tabanan. Sumber data dari penelitian ini yaitu $A A$. Ayu Ketut Agung sebagai informan kunci, penglingsir Puri Agung Kabupaten Tabanan dan selaku pemilik LKP Salon Agung, Sagung Oka Pradnyawati selaku ketua HARPI dan pemilik LKP Salon Anggun, dan Ni Made Rahayuni selaku pemilik salon Candra Dewi. Variabel dalam penelitian ini yaitu Tata Rias Pengantin Agung Kabupaten Tabanan. Instrumen penelitian dalam penelitian ini yaitu lembar observasi yang digunakan sebagai pedoman untuk memperoleh informasi terkait tata rias pengantin Agung Kabupaten Tabanan yang terdiri dari tata rias wajah, tata rias rambut, tata busana dan aksesoris yang digunakan, lembar wawancara yang digunakan untuk memperoleh gambaran terkait tata rias pengantin Agung Kabupaten Tabanan. Teknik analisis data yang digunakan yaitu teknik analisis deskriptif.

\section{HASIL DAN PEMBAHASAN}

Tata rias pengantin Agung Kabupaten Tabanan dibagi menjadi 4 bagian yaitu tata rias wajah pengantin wanita yang terdiri dari pembentukan Alis merupakan bingkai wajah seseorang dapat dikatakan dengan mencerminkan karakter seseorang. Alis yang baik dan ideal yaitu seperti "daun intaran" sebuah daun yang ujungnya tajam dan memiliki makna yaitu kekuatan wanita dalam menghadapi kehidupan, perona mata yang digunakan yaitu menyesuaikan warna busana dan tidak menggunakan 
warna merah, perona pipi digunakan agar memberikan kesan cerah pada pipi dan membentuk tulang pipi agar tampak lebih tirus, perona hidung adalah Hiasan pada hidung tidak memiliki makna khusus hanya tentang keindahan yang bertujuan agar bentuk hidung terlihat lebih sempurna, perona bibir tidak memiliki makna khusus, hanya sebagai keindahan yang berfungsi untuk mempercantik bibir, gecek merupakan hiasan pada dahi yang berwarna merah dan berbentuk bulat (berada ditengah atau diantara pangkal alis) yang digunakan sebagai hiasan pada wajah dan melambangkan kesucian, penampel pelengan hiasan pada wajah yang terbuat dari kain bludru merah yang dibentuk bulat dan diletakkan pada bagian pelipis kiri dan kanan. Memiliki makna agar pengantin mampu memfokuskan pikirannya, srinata adalah hiasan pada dahi yang berfungsi untuk membuat dahi menjadi terlihat sempurna dan indah. Makna yang terkandung didalamnya menandakan bahwa seseorang telah dewasa. Sedangkan tata rias wajah untuk pengantin pria sama seperti tata rias wajah pengantin wanita yaitu menggunakan alis, perona mata, perona pipi, perona hidung, gecek, perona bibir namun rias wajah pada pengantin pria digunakan tipis agar pengantin pria tidak terlihat pucat.

Tata rias rambut pengantin wanita terdiri dari sanggul gelung tanduk merupakan bentuk sanggul yang menyerupai tanduk yang terbuat rambut ijuk yang dibentuk hingga menyerupai tanduk, kemudian diberikan janur- janur kecil berbentuk layang-layang sebanyak 8 buah yang berfungsi sebagai penyangga hiasan kepala dan sebagai simbol keharmonisan, petitis merupakan aksesoris yang digunakan di atas dahi yang berbentuk melengkung seperti jantung hati yang bagian tengahnya meruncing dan melengkung ke kiri dan kanan yang melambangkan keindahan dan keanggunan dalam hal kebaikan, bunga hidup yaitu bunga cempaka putih, bunga cempaka kuning, bunga sandat merupakan bunga hidup yang diletakkan pada bagian depan dan bagian belakang, bunga ini berfungsi untuk memancarkan keharuman pada pengantin, bunga mawar adalah bunga hidup yang diletakkan pada bagian depan dan belakang yang melambangkan kekuatan hati seorang wanita, bancangan merupakan aksesoris yang diletakkan pada bagian tengah atas setelah dipasangkan bunga mawar dan memiliki fungsi sebagai memperindah dan penyangga untuk membentuk segitiga dari bunga emas, puspalembo adalah aksesoris yang diletakkan pada bagian samping kanan dan kiri bancangan yang berfungsi untuk mempercantik hiasan kepala dan menyambungkan bentuk dari bancangan sebagai penyangga bentuk segitiga dari bunga emas, bunga emas adalah aksesoris yang diletakkan pada bagian atas bancangan yang disusun hingga berbentuk segitiga dan berfungsi sebagai hiasan kepala yang memiliki nilai keindahan, bunga kap adalah aksesoris yang diletakkan pada bagian belakang yang berfungsi sebagai penutup tangkai bunga emas dan berfungsi sebagai pengusir hal-hal yang negatif pada pengantin, kompyong merupakan aksesoris yang dipasangkan pada bagian belakang menutupi pusungan rambut yang menjuntai kebawah yang memiliki makna sebagai penyemarak keindahan. Sedangkan tata rias rambut pengantin pria hanya menggunakan udeng emas merupakan udeng yang terbuat dari emas yang berisikan bunga pucuk emas memiliki makna sebagai pengikat Budi Indria dan melambangkan kekayaan masyarakat Kabupaten Tabanan.

Tata busana pengantin wanita terdiri dari tapih prada adalah kain pada bagian dalam yang berfungsi untuk melapisi kaki pengantin wanita dalam tata rias pengantin Agung Kabupaten Tabanan yang memiliki makna untuk menghindari perempuran dari kejahatan dan hal- hal yang tidak diinginkan, wastra songket merupakan kain yang berukuran 2 meter yang digunakan pada bagian luar untuk menutupi tubuh sebatas mata kaki yang memiliki makna keindahan dan kemewahan pada pengantin, sabuk toros adalah kain panjang yang dililitkan dari pinggul sampai bagian dada yang 
berfungsi untuk memperkuat wastra dan mengencangkan serta membentuk badan pengantin wanita, sabuk prada adalah kain yang dililitkan dari bagian dada sampai pinggul yang digunakan untuk menutupi sabuk toros/ stagen. Memiliki makna seorang wanita sudah terikat hubungan suami istri maka harus dapat menahan nafsu dan mengendalikan diri agar setia terhadap suaminya, selendang once jawa adalah selendang tenun panjang dengan motif yang mirip seperti tenunan jawa yang dililitkan pada bagian dada yang melambangkan bahwa masyarakat Kabupaten Tabanan dan jawa pernah menjalin hubungan baik, selendang ktengsun adalah selendang panjang berwarna merah yang dililitkan pada bagian pinggang dan menjuntai kedepan yang memiliki makna sebagai simbol keanggunan pengantin wanita. Sedangkan busana pengantin pria menggunakan wastra prada adalah kain panjang yang berada pada bagian dalam yang memanjang ke depan, yang digunakan oleh pengantin pria memiliki makna sebagai kegagahan dan kewibawaan seorang pria, saput songket adalah kain panjang yang digunakan pada bagian luar untuk menutupi wastra prada dan memiliki makna sebagai simbol Dewa Wisnu, umpal prada digunakan pada bagian atas busana pengantin pria yang berukuran panjang yang memiliki makna sebagai simbol Dewa Siwa dan baju kerah emas adalah baju yang pinggirannya berisi tempelan emas dengan model pendek di bagian belakangnya melengkung yang melambangkan kekayaan dari kerajaan Kabupaten Tabanan.

Aksesoris yang digunakan oleh pengantin wanita terdiri dari subeng adalah aksesoris yang digunakan pada telinga pengantin agung Kabupaten Tabanan. Subeng mempunyai makna sebagai lambang kesusilaan dan pengetahuan yang berfungsi agar kesusilaan dan pengetahuan berjalan dengan selaras, kalung adalah aksesoris yang digunakan pada bagian leher yang melambangkan pengekangan diri untuk tidak berkata kotor. Bentuk kalung yang digunakan dalam pengantin Agung Kabupaten Tabanan tidak memiliki bentuk khusus, boleh menggunakan bentuk kalung apa saja, gelang kana adalah aksesoris yang digunakan pada lengan atas tepatnya antara bahu dan siku yang memiliki makna sebagai bukti kekayaan para leluhur masyarakat Kabupaten Tabanan, gelang nagasatru adalah aksesoris yang digunakan pada pergelangan tangan kanan dan kiri pada pengantin wanita yang memiliki makna sebagai simbol kekuatan dan dapat mengekang diri, cincin adalah aksesoris yang digunakan oleh pengantin wanita pada bagian jari manis tangan kanan memiliki makna sebagai melambangkan pikiran agar pengantin selalu berpikiran baik, dan sabuk emas adalah aksesoris yang digunakan pada bagian pinggang diatas selendang ktengsun yang melambangkan keanggunan pada pengantin wanita dan mampu mengikat dan membatasi diri sebagai seorang istri. Sedangkan asksesoris yang digunakan oleh pengantin pria yaitu rumbing adalah aksesoris yang digunakan oleh pengantin pria pada bagian telinga yang dipasang dibagian kiri dan kanan dan memiliki makna sebagai keharmonisan pengetahuan dan sikap untuk mencegah sikap keegoisan dalam berrumah tangga dan keris adalah aksesoris yang digunakan oleh pengantin pria pada bagian belakang yang dikaitkan ke dalam saput/ wastra yang mengandung makna yang melambangkan purusa dan pradana (laki-laki dan perempuan) berfungsi sebagai menambahkan kegagahan dan kewibawaan seorang pria.

Tata rias pengantin Agung Kabupaten Tabanan adalah tata rias pengantin Agung yang mewah dan tinggi /utama tingkatannya yang digunakan pada saat upacara pernikahan di Kabupaten Tabanan. Tata rias pengantin Agung Kabupaten Tabanan dibagi menjadi 4 bagian yaitu tata rias wajah pengantin wanita yang terdiri dari pembentukan alis, perona pipi, hidung, perona bibir, gecek, srinata, penampel pelengan, perona mata, pengaplikasian perona mata sesuai dengan warna busana pengantin yang 
digunakan namun tidak boleh menggunakan warna merah. Hal ini diperkuat oleh penelitian Putri Astuti (2017) menyatakan pada bagian hiasan kelopak mata tidak boleh menggunakan warna merah, karena dalam bahasa Bali warna merah adalah mengandung hal buruk dapat dikatakan di Bali, orang tersebut mempelajari ilmu hitam untuk menyakiti sesamanya dengan leak barak yang matanya berwarna merah menyala dan menyeramkan. Sedangkan tata rias wajah untuk pengantin pria sama seperti tata rias wajah pengantin wanita yaitu menggunakan alis, perona mata, perona pipi, perona hidung, gecek, perona bibir namun rias wajah pada pengantin pria digunakan tipis agar pengantin pria tidak terlihat pucat.

Tata rias rambut pengantin Agung Kabupaten Kabupaten Tabanan pada pengantin wanita terdiri dari pembuatan semi yang diberikan malem dengan bentuk melengkung ke dalam menuju belakang telinga. Bentuk semi diperkuat oleh penelitian Delia Wulansari (2015) menyatakan bahwa bentuk semi melengkung ke dalam seperti engkungengkungan (sunggar jawa) dan berakhir dibelakang telingga dengan bantuan "malem", yang memiliki makna menandakan seseorang telah dewasa, baik fisik maupun rohani, berani melepaskan diri dari orang tua dan mempunyai hak dan kewajiban yang baru. Kemudian dilengkapi dengan sanggul gelung tanduk yang berisikan janur kecilkecil, petitis, bunga hidup yaitu bunga cempaka putih, bunga cempaka kuning, bunga sandat, dan bunga mawar, bancangan, puspalembo, bunga emas, bunga kap, kompyong. Sedangkan tata rias rambut pengantin pria hanya menggunakan udeng emas yang berisikan bunga pucuk emas.

Tata busana pengantin Agung Kabupaten Tabanan pada pengantin wanita terdiri dari tapih prada, wastra songket, sabuk toros, sabuk prada, selendang once jawa, selendang ktengsun. Sedangkan busana pengantin pria menggunakan wastra prada, saput songket, umpal prada dan baju kerah emas.
Aksesoris yang digunakan oleh pengantin wanita tata rias pengantin Bali Agung Kabupaten Tabanan terdiri dari subeng, kalung, gelang kana, gelang nagasatru, cincin, sabuk emas. Sedangkan asksesoris yang digunakan oleh pengantin pria yaitu rumbing dan keris. Ciri khas dari tata rias pengantin Agung Kabupaten Tabanan dilihat dari tata rias wajahnya pada pengantin wanita yaitu menggunakan penampel pelengan yang terbuat dari kain bludru merah dan pada pengantin pria menggunakan gecek pada bagian tengah dahi. Pada hiasan rambut pengantin wanita menggunakan sanggul gelung tanduk yang isikan janur-janur kecil berbentuk layang-layang dan petitis yang berbentuk jantung hati. Pada pengantin pria hiasan rambutnya menggunakan udeng emas. Pada busana pengantin wanita yang menjadi ciri khasnya yaitu menggunakan selendang once jawa dan selendang ktengsun, sedangkan pada pengantin pria menggunakan baju kerah emas. Aksesoris pada pengantin wanita ciri khasnya yaitu menggunakan kalung.

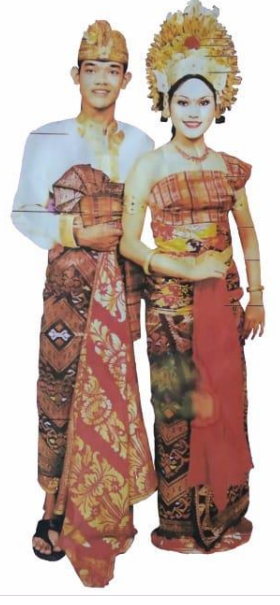

Gambar 55. Tata Rias Pengantin Agung Kabupaten Tabanan Sumber : Dokumentasi Pribadi

\section{KESIMPULAN}

Berdasarkan hasil penelitian diatas dapat disimpulkan bahwa tata rias pengantin Agung Kabupaten Tabanan adalah tata rias pengantin yang digunakan pada acara pernikahan di Kabupaten Tabanan. Tata rias pengantin ini terdiri dari tata rias wajah, tata rias rambut, tata 
busana dan aksesoris yang digunakan, tentunya tata rias pengantin Agung Kabupaten Tabanan memiliki keunikan dan ciri khas tersendiri yang berbeda dari tata rias pengantin lainnya yang ada di Bali yaitu pada tata rias wajahnya pengantin wanita meliputi srinata, perona mata, perona pipi, perona bibir, gecek dan yang menjadi ciri khas adalah penampel pelengan yang berbentuk bulat terbuat dari kain bludru merah. Sedangkan tata rias wajah pengantin pria yaitu sama dengan tata rias wajah pengantin pria lainnya.

Kemudian pada tata rias rambut pengantin wanita meliputi sanggul gelung tanduk yang berisi janur- janur kecil, petitis berbentuk jantung hati, bunga hidup yaitu bunga cempaka putih dan bunga cempaka kuning, bunga sandat dan bunga mawar masing- masing sebanyak 50 biji, bunga emas sebanyak 21 biji, bancangan, puspa lembo, bunga kap, kompyong. Sedangkan tata rias rambut pada pengantin pria menggunakan udeng emas yang berisi bunga pucuk emas.

Busana yang digunakan pada penganttin wanita meliputi tapih prada, wastra songket, sabuk toros, sabuk prada, selendang once jawa, selendang ktengsun dan aksesoris yang digunakan yaitu subeng, sabuk emas, gelang kana, gelang naga satru, cincin, kalung. Sedangkan busana yang digunakan pada pengantin pria yaitu wastra prada, saput songket, umpal prada, baju kerah emas dan aksesoris yang digunakan yaitu rumbing dan keris.

\section{SARAN}

Berdasarkan pembahasan hasil penelitian dan simpulan, maka dapat diajukan saran sebagai berikut:

1. Bagi Masyarakat, Agar
masyarakat
mempertahankan tata rias pengantin Agung Kabupaten Tabanan tanpa meninggal pakem/ keaslian dari tata rias pengantin ini sehingga generasi dan anak cucu nantinya dapat melestarikan.

2. Bagi peneliti lain, hasil penelitian ini dapat digunakan sebagai kajian pustaka dalam melakukan penelitian sejenis. Hal tersebut dapat dilakukan dengan cara membandingkan tata rias pengantin Agung Kabupaten Tabanan dengan tata rias pengantin lainnya.

3. Bagi Mahasiswa, hasil penelitian ini dapat dijadikan sebagai pedoman dalam mata kuliah tata rias pengantin Bali.

\section{DAFTAR PUSTAKA}

Agung, Dr. Anak Agung Ketut, 2004, Busana Adat Bali. Denpasar. Palawa Sari

Ari Safitri, Rizki, 2017, Tata Rias Pengantin Agung Khas Gaya Buleleng. Jurnal Bosaparis. Vol 8, No 2.

Darmika, Ida Bagus, Dkk. 1988. Arti Dari Lambang dan Fungsi Tata Rias Pengantin Dalam Menanamkan Nilainilai Budaya Bali. Jakarta : Dikbud, Dirjern Sejarah dan Nilai Tradisional.

Delia Wulansari, 2015, Bentuk, Fungsi dan Makna Tata Rias dan Prosesi Upacara Perkawinan Bali Agung di Bali. Jurnal Universitas Negeri Surabaya. Vol 04, No 2

Herni Kusantati,2008. Tata Kecantikan Kulit Jilid 3. Jakarta : Direktorat Pembinaan Sekolah Menengah Kejuruan

Mahligai, 2009:27, Inspirasi Pengantin Bali, Denpasar: DictiArt Lab, Bali: Jagad Art Space

Martha Tilaar, 2010. Tata Rias dan Busana Pengantin Solo Basahan \& Solo Putri. Jakarta: PT. Gramedia Pustaka Utama 
Jurnal Bosaparis: Pendidikan Kesejahteraan Keluarga

Volume 10, Nomor 3, November 2019

Mertani, Nyonya M, 2003. Tata Rias

Pengantin Bali, Denpasar, Upada Sastra.

Putri Astuti, Ni Putu, 2017, Tata Rias Pengantin Kabupaten Klungkung. Jurnal Bosaparis. Vol 8, No 2.

Pujiastuti, Ni Kadek, 2015, Study tentang tata rias dan busana pengantin Bali Gaya Badung, Buleleng : Skripasi Universitas Pendidikan Ganesha.

Wiartini, Kadek Lina, 2015, Study Tentang Tata Rias Pengantin Agung Kabupaten Karangasem Provinsi Bali. Jurnal Bosaparis, Vol 2, No 1.

Wibowo, 1987, Arti Lambang Dari Fungsi Tata Rias Pengantin Provinsi Daerah Istimewa Yogyakarta. Daerah Istimewa Yogyakarta: Indonesia Heritage Digital Library

Setia Bekti, 2015, 22 Desember. "Pancaran Busana Agung Pengantin Bali". Tersedia pada https://www.weddingku.com/tata-riaspengantin-bali-payas-agung-badung (diakses pada tanggal 28 April 2019).

Novita Dewi, 2018, 25 November. "Payas Agung Khas Daerah Kabupaten Tabanan". Tersedia pada https://www.nusabali.com/payaskhas-daerah-hanya-lestari-di-pkb (diakses pada tanggal 27 April 2019). 